\title{
PRESIDENTIAL ADDRESS TO THE 14th NATIONAL COUNCIL MEETING OF THE SOUTH AFRICAN SOCIETY OF PHYSIOTHERAPY
}

My period as President of the Society has been a worthwhile experience inasmuch as I have had the opportunity to take a long hard look at our organisation.

Why does a profession require an organisation and how does such a Society evolve? A group of responsible, strongly motivated and highly dedicated persons, with a particular vocational training, band together and cndeavour to formulate a code of ethics and a set f norms to which persons wishing to join such an association will undertake to conform. This will have the inmediate effect of protecting the standard and the image of that profession and, of more importance, of protecting the public from unskilled practitioners.

What are the aims of such a Society and how does it achieve them? On the one hand, it provides a forum for discussion and dissemination of knowledge and skills obtained from personal experience gained from continued research and experimentation. On the other hand, it provides a forum for the approval and discussion of policy and the implementation of such policy by means of communication with its members.

The South African Society of Physiotherapy evolved in just this manner and the future progress of physiotherapy as a profession lies in its hands.

We are constantly being reminded that we have a "professional standard" to maintain. To what are we referring? There are both academic and ethical standards. Academic standards are those judged by examination of competence, experience and demonstrated responsibilty. The qualifications thus gained enable the holder to register as a fully qualified physiotherapist (in our case with the Professional Board for Physiotherapy of the South African Medical and Dental Council). These standards are both jealously and zealously guarded by those responsible for the training programmes in this country. It is up to all those concerned to ensure that these standards are being maintained throughout the country.

When one makes an indepth study of the training of the physiotherapist of today, one appreciates just how far the profession has progressed. The emphasis has swung away from the passive to the active and the tremendous expansion of scientific knowledge and research has forced the abandonment of many an empirical technique. The elements of chance and good intention have been firmly removed. There are also many opportunities for continuing education in the post graduate fields and the eagerness that physiotherapists have shown in pursuit of this additional knowledge bears witness to their determination to further their studies and satisfy enquiring minds.

In spite of what was said at the Congress, physiotherapists are not being trained as mere technicians. Physiotherapists, as never before, are taught to think and act for themselves. They demonstrate an ability and educative skill whereby they are able to assess accurately a patient's condition and evaluate the necessary treatment based on a sound and penetrating wisdom obtained during concentrated academic and practical training at both under- and postgraduate levels. It is for this reason that the Society has made its initial approaches to the medical profession to acknowledge the capabilities of the physiotherapist and permit a wider interpretation of our Ethical Rules, as has been done in several overseas countries.

The ethical standards of physiotherapists in this country are controlled by a strict code of professional ethics laid down by both the Society and the Professional Board for Physiotherapy. These prescribe the regulations relating to professional practice and disciplinary control. It is the duty of all members of a professional society to maintain the image and status of the profession regardless of their work situation. Physiotherapists are constantly being told that they do not "sell" themselves sufficiently. This was forcefully urged by Professors André and Sandra van der Merwe at a recent interesting, stimulating and thought provoking course on "marketing" which they conducted for physiotherapists. By this is not meant that we must advertise ourselves in an unethical manner but our behaviour towards members of the public is of vital importance. It would be as well to remember the words of a prominent American researcher in professionalism, Ward Darley, who says:

"The truly professional person is one, who, by virtue of intellectual capacity, education and moral outlook is capable of the exercise of intellectual and moral judgment at a high level of responsibility."

\section{Contents - Inhoud}

Presidential Address to the 14th National Council of the South African Society of Physiotherapy

$\begin{array}{lllllllllll}\text { Abstracts } & \ldots & \ldots & \ldots & \ldots & \ldots & \ldots & \ldots & \ldots & 32, & 54\end{array}$

The "High Risk" Infant $\ldots \begin{array}{lllllll}\ldots & \ldots & \ldots & \ldots & \ldots & \ldots & 33\end{array}$

Results of Early intervention in the Baby with

Cerebral Motor Disturbance $\quad \ldots \quad$...

The At Risk Autistic Child and His Family $\ldots \begin{array}{lll}. . . & 38\end{array}$
Keeping in Touch - The Need for Communication

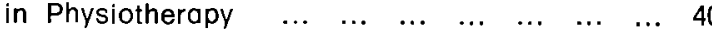

A Reappraisel of Evaluation of Final Year Student

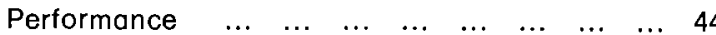

$\begin{array}{lllllllllll}\text { Obituaries } & \ldots & \ldots & \ldots & \ldots & \ldots & \ldots & \ldots & \ldots & \ldots & 50\end{array}$

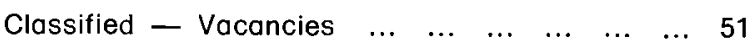


The standard of physiotherapy in South Africal compares favourably with that of other countries. However, in a country no longer considered a developing country but one that is beginning to take its place with the industrial countries of the world, the scope and facilities available for the total population are sometimes woefully inadequate.

The rapidly developing standards of living of the Black and Coloured populations will inevitably lead to an increased demand for specialised medical services. It is officially recognised in South Africa that there is, and in the foreseeable future, will be, a shortage of skilled personnel. As far as physiotherapy is concerned, in vicw of the upsurge to University education and due to insulficient tacilities and lack of suitably trained lecturing staff, the admission of additional students is often not possible, thus impeding the flow of qualifying physiotherapists. This makes it essential that the skilled personnel available are utilised to best effect, particularly in the hospital situation.

If one is going to optimise the use of highly specialised personnel, a lower level of competence must be created to cope with the work load. The merits and demerits of creating a category of "assistants" have been debated at length and it would appear that the establishment ol. such a category is inevitable. The more recent flow from the Hospital Service to the private sector has, however, created an imbalance. Every effort should therefore be made to $5 t e m$ the flow as a shortage of skilled personnel in hospital services may cventually preclude adcquate supervision of the essential in-service training which will be necessary for these assistants.

A new era lies before us. One in which we will have to prove and maintain our enhanced professional standards so that we may never feel threatened or fear that the image of physiotherapy is in any way in jeopardy by the introduction of physiotherapy assistants.

During this brief address, I have tried to stress the importance of professionalism which includes your image. The future of physiotherapy in this country lies not only in the hands of the upper echelons of the Society, but in the hands of each and every member of the profession.

Whether you respond to wild, near hysterical exhortations, or to bullying tactics of delegation, or to an earnest plea from an old-fashioned, but nevertheless dedicated, hardworking and sincere peer, my message to all professional physiotherapists is RESPOND.

K. M. Levy

\section{ABSTRACTS}

\section{Young, Cheshire, Pierce and Vivian (1977): Cervical Ankylosis with Acute Spinal Cord Injury. Paraplegia 15,133 - 144.}

This very comprehensive and well-documented discussion of the incidence of spinal cord injury in cervical ankylosis includes a paragraph on "prevention". This should be read by all those who deal with people suffering from cervical ankylosis and spondylosis. It is quoted here in full: "Persons with cervical ankylosis commonly suffer low velocity injuries, particularly in the spondylitic group. Our colleagues in rheumatology, internal medicine and general practice should be alerted to this potentiality. They should caution and instruct their patients to observe such preventive measures as having night-lights in the bedroom, bathroom and dimly-lit halls. Handrails should be available in the tub and shower. Persons with cervical ankylosis should be instructed to use handrails when ascending or descending stairs. All should conscientiously use seat belts when riding in an automobile. Above all, they should report all incidences of head and neck trauma to their physician and limit cervical motion until they can be properly examined by their physician. The initial attending physician should take care to obtain cervical films, paying particular attention to protecting vertebral alignment in the process. Such simple measures would significantly reduce the incidence of spinal cord injury in this susceptible group."

The danger of such serious trauma to the neck in these high-risk subjects is not sufficiently appreciated, and simple preventive measures like those outlined above could well save the patient from the distress attendant upon fractures of the cervical spine. The severity of the disciplines which of necessity are imposed upon him in their treatment can be well-nigh intolerable to the elderly person and the difficulties he experiences frequently prove to be insurmountable and he succumbs.

H. C. Watts
Pridmore, S. A. (1978) Heavy Resistance Exercise Without Apparatus. Austr. J. Physiother, 24, 1. A set of twelve heavy-resistance exercises has been described in which a kitchen chair is the only necessary apparatus. Their value in rehabilitation and sports training has been indicated. The mechanisms involved have been discussed.

M. J. Runnalls

Roberts, G. M., Roberts, E. E., Lloyd, K. N., Burke, M. S., Evans, D. P. (1978): Lumbar Spinal Manipulation on Trial Part II - Radiological Assessmbent. Rheum. and Rehab. 17, 54.

In a trial of manipulation for chronic low back pain, radiographs of the lumbar spine and radiographic assessment of spinal motion were of no value in predicting or assessing the response of the patients to manipulation. Although radiography of the lumbar spine is a commonly requested investigation, it contributes little to the management of such patients except to exclude serious spinal pathology before any form of physical treatment is commenced.

M. J. Runnalls

Lifting, Physiotherapy 65, 238-251 \& 277-292.

This is a comprehensive series of articles on this important subject, which includes the Biomechanics, Pathology, and Applied Anatomy and Physiology of the back in relation to lifting. Also covered are Back Care in Industry, Advising Patients on Back Care, and Physiotherapists as Teachers of the Public. There is a very well illustrated pull-out booklet which analyses and describes in detail the manoeuvres involved in effective and safe lifting. Safe, that is, from the point of view of both the patient and the lifter's back. The series provides excellent background knowledge and the booklet an equally good guide for the physiotherapist who finds herself in the position of teaching others, such as nursing staff, the techniques of correct lifting procedures.

H. C. Watts 